Uşak Üniversitesi Sosyal Bilimler Dergisi

$2015,8 / 2$

\title{
Üniversite Öğrencilerine Yönelik Müzik Performans Kaygısı Ölçeğinin Uyarlama Çalışması
}

\author{
Mehmet PALANCI \\ Zuhal ALTUN DİNÇ** \\ Uğur DOĞAN***
}

\section{Öz}

Bu çalışmanın amacı Doğan (2013)'ın doktora tezi için geliştirilen lise öğrencileri için müzik performans kaygısı ölçeği'nin üniversite öğrencilerine yönelik uyarlama çalışmasının yapılmasıdır. Çalışmaya 182 müzik bölümü üniversite öğrencisi katılmıştır. Yapı geçerliği için açımlayıcı faktör analizi yapılmış ve ölçeğin toplam varyansın \%43.52'sini açıklayan 17 madde ve 3 faktörden oluştuğu bulunmuştur. Ölçeğin orijinal formunda olan 3 maddenin üniversite öğrencilerinde işlemediği görülmüştür. Güvenirlik çalışmasında, cronbach alfa iç tutarlık katsayısı .91 , alt ölçeklerin alfa değerleri ise sirasıyla $.92, .71$ ve $.61^{\prime}$ dir. 5 hafta ara ile yapılan test-tekrartest sonucu korelasyon katsayısı .79 olarak bulunmuştur. Yapılan bir diğer güvenirlik çalışması \%27'lik alt-üst grup karşılaştırmasında tüm maddelerde anlamlı bir fark bulunmuştur. Bu bulgulara dayanarak araştırmacılar tarafından geliştirilen Lise Öğrencilerine için Müzik Performans Kaygısı Ölçeğinin üniversite öğrencilerinde de kullanılabilen bir ölçme aracı olduğunu söylenebilir.

Anahtar Kelimeler: Müzik Performans Kayg1sı, Üniversite Öğrencileri, Geçerlik, Güvenirlik.

\footnotetext{
* Yrd. Doç. Dr., Karadeniz Teknik Üniversitesi, Fatih Eğitim Fakültesi Özel Eğitim Bölümü, Trabzon Türkiye, mpalanci@ktu.edu.tr

** Yrd. Doç. Dr., Karadeniz Teknik Üniversitesi, Fatih Eğitim Fakültesi Güzel Sanatlar Eğitimi, Trabzon Türkiye, zdincaltun@hotmail.com

*** Yrd. Doç. Dr. Muğla Sıtkı Koçman Üniversitesi, Eğitim Fakültesi, Rehberlik ve Psikolojik Danışmanlık ABD, Muğla Türkiye, ugurdogn@gmail.com
} 


\title{
Music Performance Anxiety Scale for College Students: Adaptation Study
}

\begin{abstract}
The aim of this study is adapt to develop the Music Performance Scale for high school students that was developed by Doğan (2013) for college students and to show the validity and reliability of the scale. Research was conducted on 182 college students from musical department. For construct validity, exploratory factor analysis was conducted and it was found to contained 17 items and 3 factors of accounted for \%43.52 of total variance of scale. In the reliability study, it was found cronbach's alpha internal consistency coefficient .91. Alpha values of subscales ranged from .92 to .61 . Second, .79 correlation have been obtained in test-retest reliability study for scale within one month. At having done other validity study $\% 27$ up-down group comparison it was found that a meaningful difference at all items. Based on those findings, Music Performance Scale for College Students that has been adapted by the researchers, can be used in the field of educational and psychology as a valid and reliable instrument.

Key Words: Music Performance Anxiety, College Students, Validity, Reliability.
\end{abstract}

\section{Giriş}

Performans sergileme müzisyenlerin yaşamlarının kaçınılmaz bir parçasıdır. Hayatlarının belli bir bölümünde seyircinin önünde adına ister konser, ister sınav, isterse de yarışma diyelim, her müzisyen bu deneyimi yaşamak zorundadır. Performans kaygısı amatörlerden (Steptoe ve Fidler, 1987) profesyonel müzisyenlere, solistlere, orkestra müzisyenlerine ve opera müzisyenlerini de içine alan geniş bir kitleyi etkilemektedir (Kenny, Davis, ve Oates, 2004). Birçok çalışma bu problemin varlığını kesin bir şekilde ortaya koyarken, performans sergileyen müzisyenlerin yaşadığı zorlukların en önemli nedeni olduğunu belirginleştirmektedir.

Performans kaygısı müzisyenler arasında o kadar sık yaşanmaktadır ki Uluslararası Senfoni ve Opera Müzisyenleri Konferansında en çok üzerinde durulan konu (Fishbein, Middlestadt, Ottati, Straus, ve Ellis, 1988) ve Britanya Müzisyenler Birliği'ne üye popüler müzisyenlerin en fazla mustarip oldukları konudur (Cooper ve Wills (Cooper ve Wills, 1989). Yapılan bir çalışmada profesyonel müzisyenlerin \%16.5'i müzikal performanslarının yaşadıkları kaygı yüzünden zarar gördüğünü, \%21'nin performansları esnasında şiddetli bir sıkıntı yaşadıklarını ve \%16.1'nin yaşadıkları performans kaygısı yüzünden kariyerlerinin etkilendiğini 
bildirmişlerdir (Wesner, Noyes, ve Davis, 1990), ve Davis, 1990). Bunlara ek olarak, 155 senfoni müzisyeni ile yapılan bir çalışmada, çoğunluk "performansları ile ilgili kaygı olmadığında hayatlarında daha neşeli, daha mutlu, daha rahatlamış ve az stresli olduğu" fikrindedirler (van Kemenade, van Son, ve van Heesch, 1995). Bazı araştırmacilar performans kaygısının icracıların kariyerlerini vaktinden önce sonlandırmalarına yetecek bir neden olduğunu belirtirler (Nagel, 1993; Nideffer ve Hessler, 1978).

Tedavi edilmediğinde, müzisyenler için MPK genel kaygı bozukluğu ve depresyon da dahil olmak üzere çeşitli medikal ve psikolojik belirtilerin gelişmesine neden olabilir. Sonuç olarak, beta bloker kullanımı (Harris, 2001; Steptoe, 1989; Wesner ve diğ., 1990), alkol, madde kullanımı (Raeburn, Hipple, Delaney, ve Chesky, 2003) gibi uygun olmayan başaçıkma davranışlarına yönelmektedirler (Mcgrath, 2012). Yaşları 18-35 arası değişen, klasik müzik icra eden, yoğun bir şekilde profesyonel olarak bir kurumda çalışan 230 genç yetişkin ile yapılan bir çalışmada yüksek düzeyde MPK ile, bu kaygı ile başaçıkmak için madde kullanımı arasında olumlu bir ilişki söz konusudur. Bunun tam tersi olarak, yüksek düzeyde MPK ile sağlıklı yaşam tarzı arasında negatif bir ilişki mevcuttur. Araştırmacıya göre; sağlıksız başaçıkma davranışları gösteren yüksek kaygılı bireyler, ileride, diğerlerini özellikle reçeteli ilaçları kullanma konusunda etkilemektedirler (Park, 2010).

Beck ve Emery (1985) performans kaygısını kısaca, değerlendirilme kaygısı olarak tanımlar. Onlara göre değerlendirme kaygısını kaygı bozukluklarının bir kategorisi olarak görürler. Bu kaygı bireylerin kendilerini değerlendirildiklerini düşündükleri durumlarda ortaya çıar. Bu durumlar, normal sosyal etkileşimleri, topluluk önünde konuşmayı, sınav olmayı ve müzikal performansı içerir. Beck ve Emery'e göre bireyler kendilerini incinebilir hissettiklerindeki şartlar altında bu kaygıyı yaşarlar. $\mathrm{Bu}$ incinebilirlik çeşitli faktörler tarafından etkilenebilir. Birinci faktör bu değerlendirmenin durumudur. Eğer bireyler kendilerini, çevresindeki kişilerin daha az güçlü olarak algıladıklarını düşünürlerse, öz-güvenleri ve öz-yeterliklerini daha düşük algılarlar. Bir diğer faktör, bireyin kendisine olan güvenidir. Bu faktör, bireyin performans yeteneklerine ilişkin algisı tarafından şekillenir ve büyük ölçüde geçmiş deneyimleri, görevin zorluğu ve yetersiz performans için öngörülen yaptırımlardan etkilenir. Üçüncü faktör, performansın belirli ya da belirli olmayan kurallara uygunluğudur. Örneğin, topluluk önünde konuşmada, konuşma akışının belirli standartlara uygunluğu ya da konuşmanın kontrolü. Eğer birey, bu kurallara bağlı kalamadığına inanırsa, değerlendirmeyi yapacak kişilerin memnuniyetsizliğinden korkacaktır. Dördüncü faktör savaşma, kaçma, donma ve bayılma gibi ilkel refleksif tepkilerin ortaya çıkmasıdır. Bu 
tepkiler düşünme, hatırlama ve motor faaliyetleri sekteye uğratabileceğinden başarılı performans için tehlike arz etmektedir (Beck ve Emery, 1985).

MPK problemi hakkında kullanılan kavramlar benzer olabilecekken, çelişkili terminoloji kullanımı mevcuttur. Çalışmalar bu duruma alternatif olarak "sahne korkusu", performans kaygisı" ya da müzisyen stresi" olarak önermişlerdir. Çoğu ortak terminoloji kullanımı bu problemde Müzik Performans Kaygısı (MPK) teriminin kullanımını önermiştir.

\section{Araştırmanın Amacı}

$\mathrm{Bu}$ kadar uzun süredir çalışıyor olmasına ve nerdeyse her üniversitede bir güzel sanatlar fakültesi ya da eğitim fakültelerinde müzik öğretmenliği bölümü ve ülke çapında 2012-2013 eğitim öğretim yılında 91 adet Güzel Sanatlar ve Spor Lisesi öğrenci alımı yapıyor (Milli Eğitim Bakanlığı, 2012) olmasına karşın müzik performans kaygısı ile ilgili Türkiye'deki çalışmalar çok sınırlıdır (Doğan, 2013; Egilmez, 2012; Kafadar, 2009; Teztel, 2007; Yöndem, 2007, 2012). Ülkemizde lise öğrencilerine yönelik Palancı ve Doğan (2013) tarafından geliştirilen ölçek dışında ölçme aracı bulunmazken, yurtdışında Müzik Performans Kaygısını ölçmek için kullanılan çok sayıda ölçek bulunmaktadır. Yapılan bir araştırmada 22 adet performans kaygısını için geliştirilmiş ölçme aracı olduğu görülmektedir. (Osborne ve Kenny, 2005). Bu çalışmanın amacı, Palancı ve Doğan (2013) tarafından lise öğrencileri için geliştirilen müzik performans kaygısı ölçeğinin (LÖMPKÖ), üniversite öğrencileri için uyarlama çalışmasını yapmaktır.

\section{Yöntem}

$\mathrm{Bu}$ amaç doğrultusunda bu çalışmada istatistiki analiz teknikleri olarak açımlayıcı faktör analizi geçerlik çalışması, \%27'lik alt üst grup analizi, test-tekrar test ve iç tutarlılığı dayalı güvenirlik analizi yöntemleri kullanılmıştır.

\section{Çalışma Grubu}

Bu araştırmanın örneklemini 2011 - 2012 Eğitim öğretim yılı bahar döneminde Karadeniz Teknik Üniversitesi, Fatih Eğitim Fakültesi Müzik Öğretmenliği bölümlerinde öğrenim görmekte olan performans deneyimi yaşamış olan 182 üniversite öğrencisi oluşturmaktadır. 


\section{Bulgular}

\section{Yapı Geçerliği}

Verilerin faktör analizine uygunluğu Kaiser-Mayer-Olkin (KMO) katsayısı ve Barlet Testi ile incelenmiştir. Faktör analizine başlamadan önce KMO'nun 0.60'dan yüksek çıkması ve Barlett testinin anlamlı çıkması beklenmektedir (Çokluk, Şekercioğlu, ve Büyüköztürk, 2010). Bu çalışmada KMO örneklem uygunluk katsayısı .92, Barlett Sphericity testi $x^{2}$ değeri ise $1449.238(\mathrm{p}<.001)$ bulunmuş ve ölçek maddelerine verilen cevapların faktörleşebileceği görülmüştür. Alanyazında, bir maddenin faktör yük değeri için asgari büyüklügün .32 olması yönünde yaygın bir görüş vardır, bunun yanında faktör yük değerlerini değerlendirmek amacıyla yüklerin büyüklüğü için kesme noktasının ne olması gerektiğine ilişkin kararın araştırmacının tercihleri ile ilgili bir sorun olduğunu belirtilmektedir (Çokluk vd., 2010). Bu görüşten hareketle .32 faktör yük değeri benimsenmiştir. AFA'nın temel bileşenler tekniği ile promax döndürme tekniği neticesinde orijinal forma uygun olarak maddeler 3 faktör ile sınırlandırılmıştır. AFA sonucunda toplam varyansın \%43.52'sini açıklayan orijinali ile aynı şekilde 3 boyutlu bir yapıyı ulaşılmış ve orijinal formdaki Performans Öncesi Kaygı (PÖK) boyutundan "Sahne sürecinde bütün aksilikler beni bulur" ve "Kendime sürekli başaracağımı söylerim ama bu etkili olmaz" maddeleri ve Performans Esnası Kaygı (PEK) boyutundan "Solo yerine koro ile çalışmak her zaman daha iyidir" maddelerinin üniversite formunda işlemediği görülmüştür. Kalan maddelerin faktör yükleri Tablo 1'de verilmiştir. 
Tablo 1. ÜNÖMPKÖ faktör yük değerleri

\begin{tabular}{cccc}
\hline Madde No & PÖK & PEK & PSK \\
\hline 1 & .85 & .02 & .16 \\
2 & .77 & .21 & .14 \\
3 & .75 & .10 & .19 \\
4 & .74 & .32 & .18 \\
5 & .74 & .40 & .04 \\
6 & .72 & .12 & .30 \\
7 & .69 & .38 & -.05 \\
8 & .63 & .44 & .07 \\
9 & .62 & .42 & -.01 \\
10 & .59 & .34 & .25 \\
11 & .15 & .79 & .02 \\
12 & .34 & .61 & .24 \\
13 & .30 & .58 & .25 \\
14 & .20 & .53 & .26 \\
15 & .19 & .02 & .70 \\
16 & .13 & .12 & .66 \\
17 & .00 & .37 & .63 \\
\hline Faktör & 5.407 & 2.723 & 1.766 \\
Varyansı & 31.809 & 16.017 & 10.391 \\
\hline Açılanan & & \\
Varyans (\%) & & & \\
\hline ÖK: Performans Öncesi Kaygı, PEK: Performans Esnası Kaygı, PSK: Performans Sonrası Kaygı
\end{tabular}

\section{Güvenirlik Çalışması}

Ölçeğin güvenirliğini belirlemek için ölçeğin Cronbach alfa iç tutarlık katsayısı, düzeltilmiş madde-toplam korelasyonu ve testin toplam puanlarına göre oluşturulan alt \% 27 ve üst \% 27'lik grupların madde ortalama puanları arasındaki farkların sınanması için ilişkisiz t-testi kullanılmıştır. 
Tablo 2. ÜNÖMPKÖ'nin düzeltilmiş madde-toplam korelasyonu, tdeğerleri, cronbach alfa değerleri

\begin{tabular}{|c|c|c|c|c|c|}
\hline Madde no & $\begin{array}{l}\text { Ölçeğin } \\
\text { tümü için } \\
\text { MTTK }\end{array}$ & PÖK & PEK & PSK & $\begin{array}{l}\text { Alt-üst grup } \\
t \text { değerleri }\end{array}$ \\
\hline Madde 1 & .67 & .74 & & & $-15.80^{* * *}$ \\
\hline Madde 2 & .71 & .75 & & & $-15.64^{* * *}$ \\
\hline Madde 3 & .65 & .68 & & & $-13.93^{* * *}$ \\
\hline Madde 4 & .32 & .77 & & & $-15.86^{* * *}$ \\
\hline Madde 5 & .75 & .70 & & & $-15.22^{* * *}$ \\
\hline Madde 6 & .68 & .78 & & & $-12.95^{* * *}$ \\
\hline Madde 7 & .66 & .71 & & & $-11.11^{* * *}$ \\
\hline Madde 7 & .69 & .69 & & & $-15.14^{* * *}$ \\
\hline Madde 9 & .65 & .66 & & & $-11.78^{* * *}$ \\
\hline Madde 10 & .67 & .65 & & & $-9.94^{* * *}$ \\
\hline Madde 11 & .47 & & .48 & & $-7.68^{* * *}$ \\
\hline Madde 12 & .60 & & .58 & & $-11.11^{* * *}$ \\
\hline Madde 13 & .56 & & .50 & & $-10.37^{* * *}$ \\
\hline Madde 14 & .45 & & .42 & & $-8.88^{* * *}$ \\
\hline Madde 15 & .34 & & & .33 & $-7.39^{* * *}$ \\
\hline Madde 16 & .33 & & & .33 & $-6.37^{* * *}$ \\
\hline Madde 17 & 34 & & & .35 & $-6.66^{* * *}$ \\
\hline $\begin{array}{l}\text { İç } \quad \text { Tutarlılık } \\
\text { Katsayısı (Alfa) }\end{array}$ & .91 & .92 & .71 & .61 & \\
\hline $\mathrm{N}: 182^{* * *} \mathrm{p}<.001$ & & & & & \\
\hline
\end{tabular}

Cronbach Alfa Güvenirliği: Ölçeğin iç tutarlılığını belirlemek amacıyla Cronbach Alfa iç tutarlılık katsayısı değerlerine bakılmıştır. Ölçeğin tamamı için .91 , performans öncesi kaygı boyutu için .92 , performans esnası kaygı boyutu için .71 , performans sonrası kaygı boyutu için .61 bulunmuştur. Özdamar (2004)' a göre, analiz sonucunda elde edilen değer, ölçeğin güvenirliğinin kabul edilebilir düzeyde olduğunu göstermektedir.

Alt-Üst Grup Güvenirliği: Güvenirlik çalışmalarında izlenen yollardan biri de alt \% 27 ile üst \% 27 ‘lik grupların karşılaştırılması şeklinde yapılmaktadır. Gruplar arasında anlamlı bir farklılığın olup olmadığını test etmek amacıyla çalışma evreninden alınan \%27'lik alt (N:50) ve üst (N:50) grupların t-testi sonuçlarına bakılmıştır. Yapılan t-testi sonuçlarına göre, alt ve üst grup arasında anlamlı $(\mathrm{p}<$. 001) bir farkın olduğu bulunmuştur. Büyüköztürk (2007)'e göre, alt ve üst grupların maddelere verdikleri yanıtlar 
arasında fark olması ölçeğin güvenirliğini gösteren bir diğer kriterdir. Maddelerin analizine ilişkin $\mathrm{t}$ değerleri Tablo 2'de verilmiştir.

Test-Tekrar Test Güvenirliği: Ölçeğin güvenirliğini belirlemek için test-tekrar test yöntemi kullanılmıştır. 25 kişilik bir gruba 5 hafta ara ile iki uygulama yapılmıştır. Güvenirlik çalışması için Pearson Momentler Korelasyon katsayısı hesaplanmıştır. Yapılan ön test ve iki hafta sonra yapılan son test çalışmasından sonra pearson momentler korelasyon katsayısı .79 bulunmuştur. Tavşancıl (2002)'a göre güvenirlik katsayısının pozitif ve en az .70 olması beklenmektedir. Bu bilgiye göre ölçeğin güvenilir bir ölçek olduğu söylenebilir.

\section{Tartışma ve Sonuç}

Doğan (2013) tarafından geliştirilen LÖMPKÖ'nin üniversite öğrencilerine uyarlamak amacıyla planlanan çalışmada, 182 üniversite öğrencine uygulanan LÖMPKÖ'nin 20 madde olan orijinal formundan Performans Öncesi Kaygı (PÖK) boyutundan "Sahne sürecinde bütün aksilikler beni bulur" ve "Kendime sürekli başaracağımı söylerim ama bu etkili olmaz" maddeleri ve Performans Esnası Kaygı (PEK) boyutundan "Solo yerine koro ile çalışmak her zaman daha iyidir" maddelerinin üniversite öğrencilerinde işlemediği görülmüş ve ölçekten çıartılmıştır. 17 maddelik ve orjinalindeki gibi 3 boyuttan (Performans öncesi kaygı, Performans esnası kaygı ve Performans sonrası kaygı) oluştuğu görülmüştür. Ölçeğin geçerlik çalışmasında yapı geçerliğine bakılmıştır. Yapı geçerliğini belirlemek için açımlayıcı faktör analizleri yapılmıştır. Çokluk vd. (2010) ölçek geliştirme çalışmalarında açıklanan toplam varyansın \% 41'in üzerinde olmasının ve maddelerin faktör yüklerinin .32'nin üzerinde olmasının ölçeğin geçerli sayılabilmesi için yeterli olduğunu belirtmektedir. \% 41 lik açıklanan toplam varyansı sağlayabilmek için faktör yüklerini .32'nin üzerinde olanlar ölçekte bırakılmıştır. Araştırmada yapılan açımlayıcı faktör analizinde ölçek maddeleri orijinal ölçekteki gibi 3 faktör ile sınırlandırılmış, elde edilen sonuçlar bu çerçevede değerlendirildiğinde ölçekte 3 faktör altında yer alan 17 maddenin faktör yüklerinin .32 'nin üzerinde olduğu ve toplam varyansin \%43.52'sini açıklandığı görülmektedir. Sonuç olarak Üniversite Öğrencileri için Müzik Performans Kaygısı Ölçeği'nin faktör yükleri ve açıklanan varyans yüzdesi ölçek uyarlama çalışmalarında yapı geçerliği açısından yeterli olduğu görülmektedir. Böylece boyutları yalın olarak belirlenmiş, cevaplaması kolay, öğrenciler için uygun bir ölçeğin bu araştırmayla geliştirilmesinin alana önemli bir katkı sağladığı düşünülmektedir. Bu çerçevede, bu araştırmanın başlangıçtaki amacına ulaşıldığı söylenebilir. 
Yapılan güvenirlik çalışmasında, Cronbach Alfa iç tutarlılık katsayısı değerlerine, madde toplam korelasyonuna ve ölçeğin test-tekrar test yöntemine bakılmıştır. Elde edilen sonuçta ölçeğin yeterli bir güvenirlik seviyesine sahip olduğu tespit edilmiştir.

Bu ölçek ile yapılacak her bir araştırma ölçeğin daha da güçlü ölçme yapabilmesi için katkı sağlayacaktır. Ayrıca ölçeğin profesyonel ve amatör müzisyenler ile uygulanabilir hale getirilerek geçerlik ve güvenirlik çalışmaları yapılabilir. Ölçeğin yakın ve uzak erimli yordama geçerliği araştırılmalıdır.

\section{Kaynakça}

BECK, A., ve EMERY, G. (1985). Anxiety disorders and phobias: A cognitive perspective. New York: Basic Books.

BÜYÜKÖZTÜRK, Ş. (2007). Sosyal bilimler için veri analizi el kitabı (7 ed.). Ankara: PegemA Yayıncilık.

COOPER, C. L., ve WILLS, G. I. D. (1989). Popular Musicians Under Pressure. Psychology of Music, 17(1), 22-36.

ÇOKLUK, Ö., ŞEKERCIOĞLU, G., ve BÜYÜKÖZTÜRK, Ş. (2010). Sosyal Bilimler İ̧̧in Çok Değişkenli İstatistik. SPSS ve LISREL Uygulamaları. Ankara: Pegem Akademi.

DOĞAN, U. (2013). Performans Kaygısını Yordayan Değişkenlerin Yordanması ve Buna Yönelik Psiko-eğitim Programıın İşlevselliği. (Yayımlanmamış Doktora Tezi), Sakarya Üniversitesi, Eğitim Bilimleri Enstitüsü, Eğitimde Psikolojik Hizmetler Programı, Sakarya.

EGILMEZ, H. O. (2012). Music Education Students' Views Related to the Piano Examination Anxieties and Suggestions for Coping with Students' Performance Anxiety. Procedia - Social and Behavioral Sciences, 46(0), 2088-2093.

FISHBEIN, M., MIDDLESTADT, S. E., OTTATI, V., STRAUS, S., ve ELLIS, A. (1988). Medical Problems Among Icsom Musicians - Overview Of A National Survey. Medical Problems of Performing Artists, 3(1), 1-8.

HARRIS, D. A. (2001). Using B-Blockers to Control Stage Fright: A Dancer's Dilemma. Medical Problems of Performing Artists, 16(2), 72-76.

KAFADAR, A. (2009). Piyanistler Örneğinde Müzisyenlere Özgü Performans Anksiyetesi. (Yayımlanmamış Yüksek Lisans Tezi), Dokuz Eylül Üniversitesi, Güzel Sanatlar Enstitüsü, İzmir.

KENNY, D. T., DAVIS, P., ve OATES, J. (2004). Music Performance Anxiety and Occupational Stress Amongst Opera Chorus Artists and Their Relationship with State and Trait Anxiety and Perfectionism. Journal of Anxiety Disorders, 18(6), 757-777. 
MCGRATH, C. E. (2012). Music Performance Anxiety Therapies: A Review of The Literature. (Unpublished Doctoral Thesis), University of Illinois, Art in Music in the Graduate College, United States of America.

MILLI EĞITIMM BAKANLIĞI (2013). Güzel Sanatlar ve Spor Liselerine Öğrenci Alımı (Tarih-Sayı.2013/18). Ankara

NAGEL, J. J. (1993). Stage Fright in Musicians: A Psychodynamic Perspective. Bulletin of The Menninger Clinic, 57(4), 492-503.

NIDEFFER, R. M., ve HESSLER, N. D. (1978). Controlling Performance Anxiety. College Music Symposium, 18, 146-153.

OSBORNE, M. S., ve KENNY, D. T. (2005). Development and Validation of A Music Performance Anxiety Inventory for Gifted Adolescent Musicians. Journal of Anxiety Disorders, 19(7), 725-751.

ÖZDAMAR, K. (2004). Paket Programlar ile İstatistiksel Veri Analizi. Eskişehir: Kaan Kitabevi.

PALANCI, M., ve DOĞAN, U. (2013). Music Performance Anxiety Scale for High School Students: Validity and Reliability Study. International Association for Counselling Conference'da sözlü bildiri olarak sunulmuştur,Boğaziçi Üniversitesi, Istanbul.

PARK, J. E. (2010). The Relationshiop Between Musical Performance Anxiety, Healthy Lifestyle Factors, and Substance Use Among Young Adult Classical Musicians: Implications for Training and Education. (Unpublished Doctoral Thesis), Columbia University, New York, United States of America.

RAEBURN, S. D., HIPPLE, J., DELANEY, W., ve CHESKY, K. (2003). Surveying Popular Musicians' Health Status Using Convenience Samples. Medical Problems of Performing Artists, 18(3), 113-119.

STEPTOE, A. (1989). Stress, Coping and Stage Fright in Professional Musicians. Psychology of Music, 17(1), 3-11. doi: 10.1177/0305735689171001

STEPTOE, A., ve FIDLER, H. (1987). Stage Fright in Orchestral Musicians: A Study of Cognitive and Behavioural Strategies in Performance Anxiety. British Journal of Psychology, 78(2), 241-249.

TAVŞANCIL, E. (2002). Tutumların Ölçülmesi ve SPSS ile Veri Analizi. Ankara: Nodel Yayın Dağıtım.

TEZTEL, H. G. (2007). The Prevalence of Musical Performance Anxiety and Effective Coping Methods: A Study of Turkish Musicians. (Unpublished Doctoral Thesis), Istanbul Tecnical University, Social Sciences Institute, Department of Music, Istanbul.

VAN KEMENADE, J. F. L. M., VAN SON, M. J. M., ve VAN HEESCH, N. C. A. (1995). Performance Anxiety Among Professional Musicians in 
Symphonic Orchestras: A Self-Report Study. Psychological Reports, 77(2), 555-562.

WESNER, R. B., NOYES, R., ve DAVIS, T. L. (1990). The Occurence of Performance Anxiety Among Musicians. Journal of Affective Disorders, 18(3), 177-185.

YÖNDEM, Z. D. (2007). Performance Anxiety, Dysfunctional Attitudes and Gender in University Music Students. Social Behavior and Personality, 35(10), 1415-1426.

YÖNDEM, Z. D. (2012). Physical, Behavioral and Cognitive Characteristics of Perceived Performance Anxiety in Music Students: A Qualitative Study. Education and Science, 37(166). 
Z. ALTUN DINÇ, U. DOĞAN, M. PALANCI | 166 